\title{
POSSIBILIDADES E DESAFIOS DAS OUVIDORIAS NO ENFRENTAMENTO DE DENÚNCIAS DE ASSÉDIO MORAL NO AMBIENTE DE TRABALHO
}

\author{
Karla Júlia Marcelino'
}

\section{Resumo}

Este artigo tem por objetivo analisar as possibilidades e desafios das Ouvidorias frente ao Assédio Moral no ambiente de trabalho. Para tanto, fizemos uma revisão bibliográfica sobre o tema. As relações de trabalho nesta era "globalizada" caracterizam-se pela sua crescente desumanização. $\mathrm{O}$ ambiente de trabalho deveria proporcionar o desenvolvimento intelectual e um nível de satisfação crescente do trabalhador, o qual, estimulado pelas habilidades humanas de seus gestores, encontraria na organização os fatores motivacionais propícios ao atingimento de metas e realização profissional. As Ouvidorias possibilitam a intermediação entre o cidadão e a gestão do órgão, quando conseguem identificar nas denúncias recebidas as características dos casos de Assédio Moral, esclarecendo devidamente o denunciante quanto aos procedimentos cabíveis.

Palavras-chave: Assédio Moral. Gestão. Ouvidoria.

1 Graduação em Serviço Social. Foi instrutora do curso Implantação e Gestão de Ouvidoria no CEFOSPE e Gestão de Ouvidoria da Pós-Graduação na ESURP. Tem pós-graduação em Gestão Governamental (Fundação Getúlio Vargas), Gestão Pública e Serviços Sociais (UFPE) e Intervenção Psicossocial à Família no Judiciário (UFPE) e Psicologia Organizacional/NUPESF. Ministra palestras no Estado e área privada. Elaborou a Cartilha de Assédio Moral do Estado de PE. Implantou a Ouvidoria-Geral do Estado e a Rede de Ouvidores de PE. (karlajuliam@bol.com.br) 


\begin{abstract}
This article aims to analyze the possibilities and challenges of the Ombudsman's Offices in the workplace in the face of moral harassment. To do so, we did a bibliographic review on the subject. Labor relations in this "globalized" era are characterized by their increasing dehumanization. The work environment should provide intellectual development and a level of worker satisfaction that, stimulated by the human skills of its managers, would find in the organization motivational factors conducive to achievement of goals and professional achievement. The Ombudsman's Offices allow the intermediation between the citizen and the management of the organ, when he can identify the characteristics of the cases of moral harassment in the complaints received, duly clarifying the complainant as to the appropriate procedures.
\end{abstract}

Keywords: Moral Harassment. Management. Ombudsman's Office. 


\title{
1 INTRODUÇÃO
}

O Clima Organizacional deve refletir a atmosfera psicológica dos funcionários, cujo compartiIhamento de informações e relações humanas fundamentadas em valores morais e éticos influenciam diretamente a motivação, a efetividade e o compromisso desses trabalhadores. Contudo, observa-se uma crescente degradação das relações de trabalho, havendo predominância pela impessoalidade e competição nas relações interpessoais. Na pactuação de metas organizacionais nem sempre se leva em consideração a capacidade de produção de suas equipes. Embora o trabaIhador seja o capital intelectual de uma Organização, ele é facilmente descartável, quando a própria Organização apropria-se de sua produção e rapidamente o substitui por um novo funcionário com remuneração mais baixa e lucrativa. Valores como lealdade, compromisso, solidariedade, fraternidade e humanidade são rapidamente substituídos pelos resultados alcançados e capacidade de competir. Porém, as habilidades técnicas e conceituais não são suficientes para que um gestor seja um verdadeiro líder. A liderança não se institui através de decretos ou portarias. As habilidades humanas são fundamentais no ato de gerir.

Segundo RABAGLIO (2008, p. 9), "Gestão é o ato de gerir, de administrar. São os meios através dos quais se gerem uma equipe, uma instituição, um projeto ou uma empresa". Ainda segundo FLEURY (2001, p.185), "a noção de competência aparece assim associada a verbos como: saber agir, mobilizar recursos, integrar saberes múltiplos e complexos, saber aprender, saber engajar-se, assumir responsabilidades, ter visão estratégica".

CHIAVENATO (2007, p. 69) nos fala que, para o alcance dos resultados, o gestor precisa desenvolver competências fundamentais: conhecimento, habilidades, julgamento e atitudes.

\begin{abstract}
Habilidades técnicas consistem em utilizar conhecimentos, métodos, técnicas e equipamentos necessários para a realização de tarefas específicas como base em seus conhecimentos e experiência profissional [...] As habilidades humanas: consistem na capacidade e no discernimento para trabalhar com pessoas e, por intermédio delas, saber comunicar, compreender suas atitudes, motivações e desenvolver uma liderança eficaz [...] As habilidades conceituais: consistem na capacidade de lidar com ideias e conceitos abstratos. Essa habilidade permite que o administrador faça abstrações e desenvolva filosofias, valores e princípios de ação.
\end{abstract}

Nesta era de competição predatória, nossa saúde emocional vem sendo nocauteada por processos de: ansiedade, flutuação emocional, angústias, doenças psicossomáticas, individualismo, irritabilidade, Síndrome do Pensamento Acelerado, deterioração das relações sociais, dificuldade de trabalhar em equipe e cooperar socialmente. Ainda segundo CURY(2015, p. 81), "uma pessoa cartesiana, excessivamente lógica, que não admite falhas e erros, torna-se uma bomba para seu próprio cérebro, um carrasco de sua saúde emocional e um franco-atirador que mata a tranquilidade de seu cônjuge, de seus filhos, seus amigos, seus colegas de trabalho".

Estudos recentes realizados pela Organização Internacional do Trabalho (OIT) e da Organização Mundial de Saúde (OMS) indicam que o assédio moral poderá se converter no principal problema do mundo globalizado, caracterizado como o "mal-estar na globalização", atingindo o psicológico e o emocional dos cidadãos, podendo desencadear ondas de depressão, angústia e 
outros danos psíquicos em expressivos segmentos de trabalhadores. $\mathrm{O}$ assédio moral configura-se nas situações sistemáticas e prolongadas de humilhação e perseguição a que são submetidos os trabalhadores no exercício de suas funções durante a sua jornada de trabalho.

A lei estadual de Pernambuco $n^{\circ} 13.314 / 2007$, em seu artigo $2^{\circ}$, define:

[...] considera-se prática de assédio moral, no âmbito da Administração Pública, toda ação repetitiva ou sistematizada praticada por agente e servidor de qualquer nível que, abusando da autoridade inerente às suas funções, venha causar danos à integridade psíquica ou física e à autoestima do servidor, prejudicando também o serviço público prestado e a própria carreira do servidor público.

A médica psiquiatra francesa Marie-France Hirigoyen (2002, p. 65), uma das mais importantes estudiosas do assunto em todo o mundo, identifica o Assédio Moral no trabalho como "qualquer conduta abusiva (gesto, palavra, comportamento, atitude...), que atente, por sua repetição ou sistematização, contra a dignidade ou integridade psíquica ou física de uma pessoa, ameaçando seu emprego ou degradando o clima de trabalho".

Na Cartilha de Assédio Moral, publicada pela Ouvidoria-Geral do Estado de Pernambuco (PERNAMBUCO, 2015), consta que

O assédio moral constitui um dos temas que mais têm sido discutidos na atualidade, no que se refere ao trabalho e ao trabalhador, comprometendo a dignidade, as suas relações afetivas e sociais. É importante considerar que o assédio moral apresenta contornos especiais no serviço público, em razão da garantia da estabilidade do vínculo funcional. A falta de clareza e discernimento quanto às situações vivenciadas no ambiente de trabalho que se configuram como assédio requer uma maior divulgação do tema e possível prevenção. Acrescente-se, também, o receio de possíveis retaliações ou perseguições por parte das vítimas, quando elas denunciam a situação de assédio moral nas Ouvidorias. Em face da difusão dessa prática, é relevante que o tema seja discutido por toda a sociedade, especialmente pelos servidores públicos, constituindo-se as Ouvidorias num canal de intermediação desse processo.

Assédio Moral é a exposição do trabalhador a situações humilhantes e constrangedoras, repetitivas e prolongadas durante a jornada de trabalho e no exercício de suas funções. Normalmente o assediador não escolhe o seu alvo de forma aleatória, mas sim devido ao fato de a vítima destacar-se por possuir qualidades ou habilidades que ele não tem.

No processo de identificação de Assédio Moral, serão elencadas algumas de suas características:

- O prolongamento no tempo, pois o episódio esporádico não o caracteriza.

- A intensidade da violência psicológica.

- A intenção de ocasionar um dano psíquico ou moral ao empregado para marginalizá-lo no seu ambiente de trabalho.

- A conversão, em patologia, em enfermidade que pressupõe diagnóstico clínico dos danos psíquicos. 
- A vítima escolhida é isolada do grupo sem explicações, passando a ser hostilizada, ridicularizada, inferiorizada, culpabilizada e desacreditada diante dos demais.

- O assediador adota comportamento de Assédio Moral. A vítima apresenta sinais de ter sido atingida. $O$ assediador persiste no Assédio Moral. A vítima apresenta prejuízos na saúde e nas funções. A vítima é afastada ou afasta-se.

- A humilhação repetitiva e de longa duração interfere na vida do trabalhador de modo direto, comprometendo sua identidade, dignidade, relações afetivas e sociais, ocasionando graves danos à saúde física e mental.

\subsection{Situações de Assédio Moral no Ambiente de Trabalho (BARRETO, 2004)}

- Dar instruções confusas e imprecisas.

- O bloqueio ao trabalho e a atribuição de erros imaginários.

- Ignorar a presença de funcionário na frente de outros.

- Solicitar trabalhos urgentes sem necessidade.

- Solicitar ao trabalhador realizar tarefas abaixo de sua capacidade profissional.

- Fazer comentários maldosos em público.

- Não cumprimentar.

- Impor horários injustificados ou forçar o trabalhador a pedir demissão.

- Impedir o trabalhador de almoçar ou conversar com um colega.

\subsection{Consequências do Assédio Moral no Ambiente de Trabalho, Segundo o Minis- tério do Trabalho e Emprego (BRASIL, 2009, p. 26)}

- Queda da produtividade e menor eficiência.

- Alteração na qualidade do serviço/produto e baixo índice de criatividade.

- Imagem negativa da empresa perante os consumidores no mercado de trabalho.

- Troca constante de empregados, implicando o acréscimo de despesas com rescisão, seleção e treinamento de pessoal.

- Ações trabalhistas decorrentes das rescisões, inclusive com pedido de reparação de danos morais.

- Acidente de trabalho, dano aos equipamentos e doenças profissionais.

\subsection{Esclarecimentos Úteis Quanto ao Assédio Moral}

- Uma única ofensa não caracteriza o Assédio Moral, o qual se tipifica por condutas abusivas, vexatórias e humilhantes, de forma repetitiva e prolongada no tempo.

- O Assédio Moral é diferente do Assédio Sexual. Este último é uma conduta tipificada como 
crime no Código Penal e necessariamente tem como autor um superior hierárquico ou ascendente, visando a uma vantagem ou a um favorecimento sexual. O Assédio Moral, ao contrário, ainda não está tipificado como crime no Código Penal, bem como não visa obter uma vantagem sexual, e sim desestabilizar emocionalmente a vítima, a fim de que desista do emprego.

- As vítimas apresentam alguns sintomas em comum, como crises de choro, insônia ou sono excessivo, dores de cabeça, tonturas, aumento da pressão arterial, dores generalizadas, sentimento de inutilidade, depressão etc. Em casos extremos, o assédio pode levar a vítima à tentativa de suicídio ou à morte.

- É importante que a vítima anote todas as informações detalhadas do assédio, tais como: dia, hora, local, e, ainda, se alguém presenciou a cena. É importante que guarde eventuais provas escritas do assédio moral, ou seja, bilhetes com xingamentos, ofensas por escrito etc. Também é de extrema importância o depoimento de testemunhas que presenciaram as condutas do assediador ao longo do tempo.

- O Assédio Moral pode ser praticado por qualquer colega de trabalho. Embora a situação mais comum seja a do Assédio Moral partir de um superior para um subordinado, muitas vezes pode ocorrer entre colegas de mesmo nível hierárquico, ou mesmo partir de subordinados para um superior, sendo este último caso, entretanto, mais difícil de se configurar.

- É recomendável que a pessoa leve o caso ao conhecimento dos superiores hierárquicos do assediador e/ou aos Recursos Humanos do órgão, ou seja, a pessoa inicialmente deve tentar resolver o caso amigavelmente. Caso nenhuma atitude seja tomada pelo órgão no sentido de acabar com o constrangimento, a vítima deve procurar uma Ouvidoria para agilizar as providências cabíveis.

\section{OUVIDORIAS E O ASSÉDIO MORAL}

Qual seria o papel das Ouvidorias quanto ao enfrentamento das denúncias de Assédio Moral? As Ouvidorias possibilitam a intermediação entre o cidadão e a gestão do órgão, quando conseguem identificar ou não nas denúncias recebidas as características dos casos de Assédio Moral, esclarecendo devidamente o denunciante quanto aos procedimentos cabíveis. Elas fundamentam-se no tripé: qualidade, informação e controle, sendo um canal legítimo para coparticipação do cidadão na gestão. Neste sentido, o Ouvidor tem um desafio a superar no seu cotidiano profissional: interpretar fidedignamente os anseios dos cidadãos/usuários, mediar e conciliar os conflitos e cobrar das áreas responsáveis as possíveis soluções para o atendimento dessas demandas.

Não é fácil formular uma denúncia de Assédio Moral em uma organização. O medo do funcionário de sofrer uma retaliação em decorrência de sua denúncia formulada, o descrédito quanto a uma necessária apuração por parte do próprio órgão, a dificuldade de reunir provas para uma possível apuração, assim como o receio das testemunhas em testemunhar são alguns fatores 
que prejudicam o registro de manifestações sobre Assédio Moral nas Ouvidorias. Acrescente-se, ainda, o desconhecimento por parte das equipes das Ouvidorias quanto ao tema, o que dificulta as orientações necessárias aos trabalhadores de sua própria organização.

Observa-se que, no banco de dados de uma Ouvidoria, é comum o assunto Assédio Moral ser desdobrado em vários outros, como: Má conduta do Gestor, Abuso Moral, Reclamação do atendimento etc. A tipificação do assunto requer clareza por parte da própria equipe, ao registrar a manifestação, considerando que a falta de informações precisas, a ausência de um maior detalhamento dos fatos e possíveis provas poderão levar ao arquivamento da própria denúncia formulada ou mesmo inviabilizar a instauração de um possível Processo Administrativo Disciplinar. Uma denúncia, ao ser registrada numa Ouvidoria, não deverá ser fundamentada pela "subjetividade", ou seja, baseada apenas em sentimentos ou no próprio ponto de vista pessoal do denunciante, sendo a denúncia uma comunicação verbal ou escrita que indica irregularidade ou indício de irregularidade na administração e/ou no atendimento pela organização. O grau de prioridade de uma denúncia deverá sempre ser alto no seu banco de dados, surgindo a dificuldade não só do cumprimento de prazos por parte das áreas demandadas, como também a do próprio denunciado admitir que esteja praticando o Assédio Moral, quando ele envia à Ouvidoria respostas evasivas que sequer respondem ao teor da denúncia formulada.

Não cabe à Ouvidoria emitir parecer sobre a veracidade ou não da denúncia formulada, mas sim a devida orientação sobre o tema e o necessário registro da denúncia para os procedimentos cabíveis. Quando a manifestação é encaminhada de forma anônima, por meio de e-mail ou mesmo de site, torna-se impossível à Ouvidoria entrar em contato com o denunciante. No atendimento presencial ou por meio do 0800 (quando este último existe), é possível à equipe técnica esclarecer ao denunciante as opções pelo anonimato, o sigilo ou a identificação da manifestação.

Por não ser uma "resolvedoria", a Ouvidoria terá um papel claro: intermediar junto à gestão a demanda encaminhada pelo cidadão, nesse caso o próprio servidor, e cobrar da área denunciada os procedimentos adotados e a necessária resposta ao denunciante. Portanto, a Ouvidoria não atua como correição (papel da Corregedoria) ou na fiscalização (ação peculiar ao Ministério Público), mas poderá subsidiar uma possível instauração de um Processo Administrativo Disciplinar, considerando-se que a denúncia foi registrada no seu banco de dados. Para tanto, o teor da manifestação deverá apresentar o detalhamento recomendável, contendo informações precisas e sujeitas a uma possível apuração por parte do próprio órgão. O papel da Ouvidoria é de fundamental importância quando, primando pela qualidade do atendimento, realiza os procedimentos técnicos de não apenas registrar, encaminhar e cobrar das áreas responsáveis a resposta devida, comunicando ao servidor as providências tomadas pelo órgão, mas também de levar ao conhecimento do gestor máximo, inclusive através de seus relatórios gerenciais (contendo um parecer técnico devidamente elaborado e fundamentando com dados estatísticos que retratam fidedignamente o seu banco de dados), a ocorrência ou mesmo reincidência da prática de Assédio Moral na organização. Neste sentido, a elaboração de relatórios gerenciais por parte da Ouvidoria fundamentará a análise técnica quanto à prática de Assédio Moral na organização, possibilitando inclusive subsidiar as áreas de Recursos Humanos e do próprio Planejamento da organização quanto às ações de prevenção ou mesmo de combate de tais práticas. 
A sistematização das informações e a sua análise qualitativa, através de relatórios gerenciais, possibilitarão à Ouvidoria, enquanto instrumento de gestão, dar visibilidade às medidas corretivas necessárias para que não haja reincidência sistemática de assuntos relativos à ineficiência da prestação de serviços, do atendimento realizado pela organização ou mesmo de irregularidades cometidas por gestores, servidores e/ou o atendimento e serviços que lhes foram prestados.

Salienta-se, ainda, que a Ouvidoria não deverá ser a primeira instância de recebimento da denúncia de Assédio Moral. Recomenda-se que o assediado, em não conseguindo resolver a questão na esfera individual, faça o devido registro por escrito da denúncia e a encaminhe para uma chefia superior hierárquica ou para a área de Recursos Humanos de sua organização, a fim de se agilizarem as providências necessárias. O gestor máximo deverá estar ciente dessas denúncias, as quais poderão ser encaminhadas pela própria Ouvidoria à outra esfera de poder, quando constatada a sua ineficiência na necessária apuração da denúncia, podendo o próprio órgão vir a ser notificado judicialmente, o que poderá gerar desgastes para o próprio gestor máximo, além de possíveis indenizações vultosas.

No Assédio Moral Organizacional, o propósito é atingir o trabalhador por meio de estratégias organizacionais de constrangimento, com o objetivo de melhorar a produtividade e reforçar o controle. Quando se pactuam metas inatingíveis, desconsiderando os limites de produtividade de suas próprias equipes, num clima absolutamente desumanizador, estabelecem-se as condições favoráveis à prática de Assédio Moral Organizacional. As denúncias não são devidamente apuradas pela organização, a qual prefere engavetá-las ou, no máximo, transferir a vítima de uma área para outra, sem que medidas eficazes sejam tomadas para combater a própria prática do Assédio e uma possível reincidência por parte do assediador. A vítima acaba sendo culpabilizada e estigmatizada pela organização. Acrescenta-se ainda a falta de investimento em capacitações no sentido de desenvolver habilidades humanas tão necessárias aos atuais gestores. Este cenário favorece a prática de Assédio Moral pela própria ineficiência do órgão no que diz respeito à prevenção ou combate de tais abusos, refletindo a fragilidade dos mecanismos de controle interno da própria gestão.

\section{CONSIDERAÇÕES}

As relações de trabalho nesta era "globalizada" caracterizam-se pela sua crescente desumanização. O ambiente de trabalho deveria proporcionar o desenvolvimento intelectual e um nível de satisfação crescente do trabalhador, o qual, estimulado pelas habilidades humanas de seus gestores, encontraria na organização os fatores motivacionais propícios ao atingimento de metas e realização profissional. Contudo, observa-se a degradação das relações de trabalho, sendo o Assédio Moral uma crescente tendência na atualidade.

A prática do Assédio Moral é mais comum do que se supõe. Ela torna-se sutil, através de comentários indevidos, brincadeiras, atitudes e procedimentos que têm por objetivo denegrir a imagem profissional ou a trajetória que o trabalhador vem percorrendo na organização, desmoralizando-o diante dos demais colegas de trabalho, atingindo a sua autoestima e, consequentemente, impossibilitando-o de atingir as metas organizacionais. Quando se pactuam metas inatingíveis, des- 
considerando os limites de produtividade de suas próprias equipes, num clima absolutamente desumanizador, estabelecem-se as condições favoráveis à prática de Assédio Moral Organizacional.

A Ouvidoria inserida neste contexto, enquanto canal constituído para intermediar as demandas dos seus cidadãos/usuários e a própria gestão, deverá realizar todos os procedimentos necessários no recebimento de denúncias de Assédio Moral, inclusive levando ao conhecimento do gestor máximo da organização a ocorrência ou mesmo reincidência dessas denúncias, as quais poderão ou não ser apuradas através de um Processo Administrativo Disciplinar pela organização. Através de seus Relatórios Gerenciais, possibilitará, inclusive, subsidiar as áreas de Recursos Humanos e do próprio Planejamento da organização quanto às ações de prevenção ou mesmo de combate a tais práticas.

Torna-se urgente a necessidade de que o tema Assédio Moral seja amplamente discutido, bem como o próprio papel das Ouvidorias quanto às possibilidades e desafios no enfrentamento das denúncias de Assédio Moral no ambiente de trabalho.

\section{REFERÊNCIAS}

BRASIL. MINISTÉRIO DO TRABALHO E EMPREGO. Assédio moral e sexual no trabalho. Brasília: MTE, ASCOM, 2009. p. 26.

BARRETO, Margarida Maria Silveira. Assédio moral: o risco invisível no mundo do trabalho. Disponível em: www. redesaude.org.br/jr25/html/body_jr25 -margarida.html. Acesso em: 10 jun. 2017.

CHIAVENATO, Idalberto. Administração: teoria, processo e prática. 4. ed. Rio de Janeiro: Elsevier, 2007. p. 69.

Assédio Moral: trabalho, doenças e morte em: Seminário Compreendendo o Assédio Moral no Ambiente de Trabalho, São Paulo, 2010, p. 18. Disponível em: www.assediomoral.ufsc.br/?page_id=41 6 Acesso em: 9 out. 2015

CURY, Augusto. Gestão da Emoção: técnicas de coaching emocional para gerenciar a ansiedade, melhorar o desempenho pessoal e profissional e conquistar mente livre e criativa. São Paulo: Saraiva, 2015. p. 81.

FLEURY, A.; FLEURY, M. Estratégias empresariais e formação de competências: um quebra-cabeça caleidoscópico da indústria brasileira. 3. ed. São Paulo: Atlas, 2006. p. 185.

HIRIGOYEN, Marie France. Mal-estar no trabalho: redefinindo o assédio moral. São Paulo: Ed. Bertrand do Brasil, 2002

PERNAMBUCO. Lei n 13.314, de 15 de outubro de 2007. Disponível em: www.ouvidoria.pe.gov.br. Acesso em: 9 jul. 2017.

OUVIDORIA-GERAL DO ESTADO. Cartilha de assédio moral no ambiente de trabalho: prejuízos causados por condutas profissionais abusivas e vexatórias. Disponível em: www.ouvidoria.pe.gov.br. Acesso em: 01 jul. 2017.

RABAGLIO, Maria Odete. Gestão por competência: ferramentas para atração e captação de talentos humanos. Rio de Janeiro: Qualitymark, 2008. p. 9. 